\title{
Comparison of Neointimal Response between Durable-Polymer Everolimus-Eluting Stent and Bioabsorbable-Polymer Everolimus-Eluting Stent for Severely Calcified Lesions Requiring Rotational Atherectomy Serial OCT Analysis
}

\author{
Yuji Matsuda, ${ }^{1}$ MD, Takashi Ashikaga,${ }^{2,3}$ MD, Taro Sasaoka, ${ }^{3}$ MD, Yu Hatano, ${ }^{3}$ MD, \\ Tomoyuki Umemoto, ${ }^{3} \mathrm{MD}$, Tetsumin Lee, ${ }^{3} \mathrm{MD}$, Taishi Yonetsu, ${ }^{3} \mathrm{MD}$, \\ Yasuhiro Maejima, ${ }^{3}$ MD and Tetsuo Sasano, ${ }^{1,3}$ MD
}

\begin{abstract}
Summary
Clinical outcomes after percutaneous coronary intervention (PCI) for severely calcified lesions remain poor. The purpose of this study was to investigate the neointimal response after everolimus-eluting stents (EES) for severely calcified lesions treated with rotational atherectomy (RA) using optical coherence tomography (OCT).

We retrospectively analyzed 34 lesions in which PCI was performed with EES deployment following RA and OCT was performed immediately after PCI and at follow-up (nine months). The EES was either durablepolymer (DP) EES (22 lesions) or bioabsorbable polymer (BP)-EES (12 lesions). Strut coverage and malapposition were evaluated at 1-mm intervals of cross-section (CS) by serial OCT analysis. Malapposed strut was defined as having the distance from luminal border $>100 \mu \mathrm{m}$.

A total of 11,823 struts immediately after PCI and 11,720 struts at follow-up were analyzed. Immediately after PCI, the strut-level analysis showed no significant differences in the percentage of malapposed struts between the DP-EES group and the BP-EES group. At follow-up, the BP-EES group showed a more prevalent covered strut compared with the DP-EES group (strut-level analysis: 95\% versus 97\%, $P=0.045$; CS-level analysis: $97 \%$ versus $100 \%, P<0.01$; lesion-level analysis: $27 \%$ versus $83 \%, P<0.01$, respectively).

In severely calcified lesions requiring RA, the BP-EES group achieved better neointimal coverage than the DP-EES group at nine months. Additional prospective studies are needed.
\end{abstract}

(Int Heart J 2020; 61: 665-672)

Key words: Intravascular imaging, Percutaneous coronary intervention, Coronary artery disease

$\mathrm{F}$ ollowing the introduction of second-generation drug-eluting stents, the rate of stent failure has decreased $(2.0-8.5 \%){ }^{1-3)}$ However, for severely calcified lesions requiring rotational atherectomy (RA), the failure rate remains high even with the use of secondgeneration drug-eluting stents $(7.5-25.0 \%){ }^{4-6)}$ The neointimal response to stent struts in severely calcified lesions has not been well elucidated, although pathological studies have shown that stent failure including late stent thrombosis is associated with the extent of neointimal coverage of stent struts ${ }^{7-9}$. In this study, we evaluated the stent strut circumference in these lesions both immediately after PCI and after a nine-month follow-up. In addition, we compared neointimal responses in terms of polymer types of everolimus-eluting stent (EES), using serial analysis of optical coherence tomography (OCT).

\begin{abstract}
Methods
Study design and study population: Between May 2011 and March 2018, we retrospectively enrolled 169 consecutive lesions in 152 patients who underwent conventional PCI with RA at the Tokyo Medical and Dental University Hospital. Among these lesions, those that underwent OCT both immediately after the PCI and at the nine-month follow-up were included. DESs were composed of durable polymer (DP)-EES or bioabsorbable polymer (BP)-EES. Lesions treated without any stent deployment, those treated with other stent designs, or those with poor quality OCT images were excluded (Figure 1). In enrolled lesions, we researched clinical and procedural characteristics, and also evaluated the state of stent both immediately
\end{abstract}

From the ${ }^{1}$ Department of Cardiovascular Medicine, Graduate School of Medical and Dental Science, Tokyo Medical and Dental University, Tokyo, Japan, ${ }^{2}$ Department of Cardiology, Japanese Red Cross Musashino Hospital, Tokyo, Japan and ${ }^{3}$ Department of Cardiovascular Medicine, Faculty of Medicine, Tokyo Medical and Dental University, Tokyo, Japan.

Address for correspondence: Yuji Matsuda, MD, Department of Cardiovascular Medicine, Graduate School of Medical and Dental Science, Tokyo Medical and Dental University, Yushima 1-5-45, Bunkyo-ku, Tokyo, 113-8510, Japan. E-mail: matsuda.0219.circ@ gmail.com

Received for publication November 30, 2019. Revised and accepted April 16, 2020.

Released in advance online on J-STAGE July 18, 2020.

doi: 10.1536/ihj.19-648

All rights reserved by the International Heart Journal Association. 


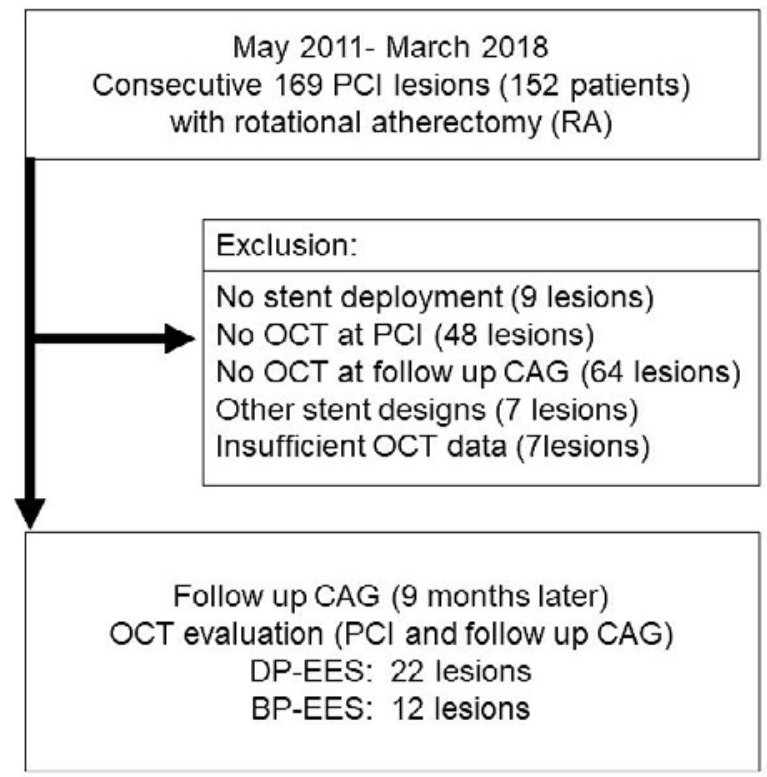

Figure 1. Study design. PCI indicates percutaneous coronary intervention; OCT, optical coherence tomography; DP-EES, durable polymer everolimus eluting stent; and BP-EES, bioabsorbable-polymer everolimus eluting stent

after the PCI and at the nine-month follow-up, comparing DP-EES with BP-EES.

All clinical, laboratory, and demographic characteristics of patients were retrieved from hospital files and computer records at our institution. All procedures and protocols involving human participants were performed in accordance with the ethical standards laid down in the Declaration of Helsinki (as revised in Brazil in 2013). Ethical approval was obtained from the institutional review board at the Tokyo Medical and Dental University Hospital.

PCI procedures: We performed RA with the Rotablator Rotational Atherectomy System (Boston Scientific, MA, USA) through a radial or femoral approach when the entire circumference of the superficial calcified plaque at the lesion was observed by OCT or intravascular ultrasound imaging. A 0.009-inch RotaWire Floppy guide wire (Boston Scientific, MA, USA) was advanced and exchanged with another guide wire via a microcatheter. In all cases, one or two burrs were chosen in order to reduce the incidence of the no-reflow phenomenon. The burr size was $1.25,1.50$, or $1.75 \mathrm{~mm}$ depending on the minimal residual lumen diameter of the lesions. A dyna-glide technique was used to advance the burr through a guiding catheter to reduce friction, and the atherectomy was performed at the speed of $180,000 \mathrm{r} /$ minute. The duration of the RA application was 15-20 seconds, with immediate termination if the speed dropped by $>5,000 \mathrm{r} /$ minute from baseline. ${ }^{10,11)}$ A saline-based flush solution including heparin and vasodilators irrigated the catheter sheath to loosen and cool the rotating parts during RA. ${ }^{9)}$ EES were deployed with or without scoring balloon dilatation following successful modification of the plaque identified by OCT or intravascular ultrasounds imaging. After implantation of the EES, post-balloon dilatation was performed with a non-compliant balloon at high pressure in cases of underexpansion or stent malapposition. Below $20 \%$ of the residual stenosis was judged as an angiographic success.

OCT measurement: In the present study, OCT technology was used for intracoronary imaging. Either ILUMIEN OPTIS (Abbott, Illinois, US) OCT systems or Lunawave (Terumo Corporation, Tokyo, Japan) optical frequency domain imaging based on OCT technology systems was used to evaluate the intracoronary stent strut conditions. These OCT systems included intravascular OCT catheter (Dragonfly; Abbott, Illinois, US or Fastview; Terumo Corporation, Tokyo, Japan), and the OCT images were analyzed using a proper OCT software. OCT images with enough quality to analyze ordinarily require approximately 10-14 mL of contrast media to remove blood cells in the target vessel. Dextran is used instead of the contrast media only if the patient eGFR is below $45 \mathrm{~mL} / \mathrm{minute} / 1.73$ $\mathrm{m}^{2}$. For serial comparisons, cross-sectional OCT images were analyzed frame by frame at $1.0-\mathrm{mm}$ intervals. Cross sections (CS) with poor quality images and struts located at a side branch or double stent areas were excluded from the present study.

All OCT images observed conformed to the previous consensus standards and reports. ${ }^{12-15)}$ Each lesion was divided into three calcium types (spotty, sheet, and calcified nodule). Spotty calcium was defined as superficial calcium with lying fibrous tissue, and sheet calcium was defined as sheet-like superficial calcific plate without visible overlying fibrous tissue. Calcified nodule was defined as protruding calcific mass without eruptive nodules. ${ }^{14,15}$ The qualitative analyses assessed the state of coverage and apposition of each strut and the presence of stent-edge dissection. Malapposition was defined as a stent-adjacent vessel lumen distance of over $100 \mu \mathrm{m}$. If a stent strut met the criteria of malapposition, it was defined as malapposed. Otherwise, an embedded strut or a protruding strut was defined as a well-apposed strut. At follow-up evaluations, previous consensus standards have indicated five categories for classification of strut outcomes: (1) covered and embedded struts; (2) covered and protruding struts; (3) covered and malapposed struts; (4) uncovered and apposed struts; and (5) uncovered and malapposed struts. ${ }^{12,13)}$ Based on these five categories, we have reclassified and simplified the outcomes into only three categories for the present study: (1) covered and embedded or protruding struts were defined as covered struts; (2) uncovered and apposed struts were defined as uncovered; and (3) covered or uncovered malapposed struts were defined as malapposed struts (Figure 2). This simplification allowed focus specifically on the evaluation of strut coverage and allowed for distinguishing permanent malapposed strut and late acquired malapposed strut from the other struts. Quantitative analyses included: (1) calcium arc; (2) minimum calcium thickness; (3) calcium length; (4) mean and minimal lumen area; (5) mean and minimal stent area; (6) lumen symmetry index; (7) in-stent lumen expansion; (8) maximum malapposition distance and malapposition length; and (9) mean neointimal area and volume. ${ }^{12-14)}$

Statistical analysis: Categorical variables are described using frequencies and percentages, and continuous variables are indicated as mean \pm standard deviation or medi- 

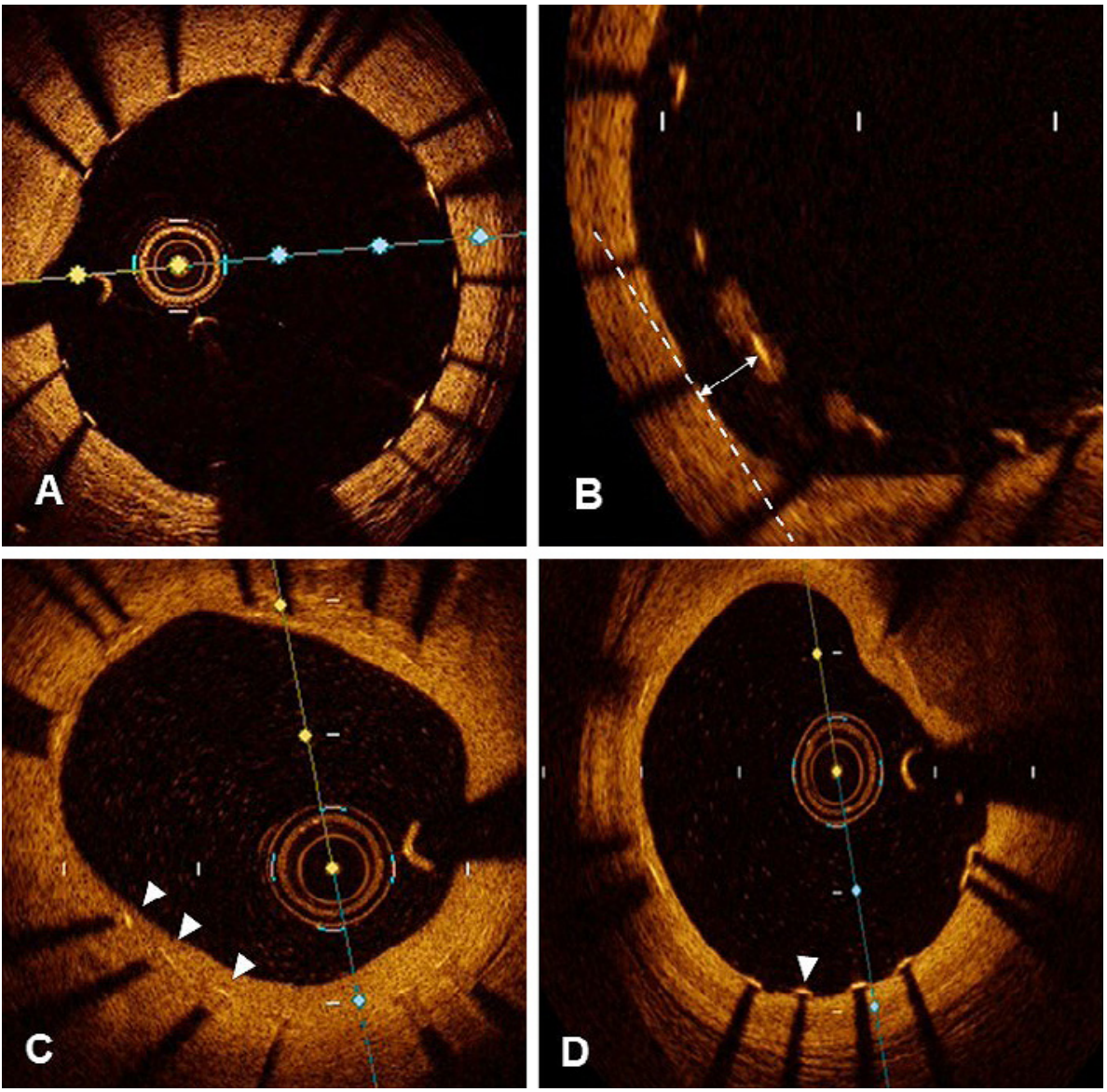

Figure 2. Representative optical coherence tomography images. A: Well-apposed stent struts. B: Malapposed stent struts. The white arrow shows distance between the stent strut and the lumen vessel $(>100 \mu \mathrm{m})$. C: Covered struts (white arrows). D: Uncovered struts (a white arrow)

ans (with interquartile ranges). A $P$-value $<0.05$ was considered significant. Independent samples $t$-test or MannWhitney $U$-test was used to compare continuous variables. Categorical variables were compared using the Chi square test $\left(\chi^{2}\right)$. Both univariate and multivariate logistic regression analyses were performed to evaluate the clinical factors affecting EES strut coverage. The dependent variable was a greater level of strut coverage, using lesion-level analysis nine months after PCI. We set the cut-off of greater neointimal coverage as lesions with all $\mathrm{CS}<30 \%$ uncovered strut. Variables with $P<0.2$ in the univariate analysis or clinically related to the strut coverage were entered into the multivariate logistic models. All statistical analyses were performed using $\mathrm{JMP}^{\circledR} 14$ (SAS Institute Inc., Cary, NC, US).

\section{Results}

A total of 11,823 struts immediately after the PCI and 11,720 struts at follow-up CAG were analyzed. We identified 34 lesions in 32 patients (DP-EES: 22 lesions 22 patients, BP-EES: 12 lesions 11 patients (Figure 1)).

Patient, lesion, and procedural characteristics are shown in Table I. Both groups were similar except but for the rate of prasugrel prescription and the estimated glomerular filtration rate although none of them were statistically significant. The stent designs are shown in detail in Supplemental Table I.

The cumulative incidence of urgent revascularization and target lesion revascularization at follow-up comprised one case $(2.9 \%$ of total lesions) and three cases $(8.8 \%$ of total lesions), respectively (Supplemental Table II).

QCA analysis showed that acute lumen gains occurred immediately after PCI and late lumen loss at follow-up CAG was not significantly different between the two groups (Table II).

Lesion characteristics obtained from OCT findings were similar between the two groups (Table III). Immediately after PCI, although the maximum malapposition distance in the DP-EES group was significantly shorter than in the BP-EES group (0.4 [interquartile rage, $0.2-0.5$ ] $\mathrm{mm}$ versus 0.6 [interquartile rage, $0.5-0.8$ ] $\mathrm{mm}, P=0.02$ ), strut-level analysis of OCT findings showed there were no significant differences in the percentage of malapposed struts $(9.5 \pm 6.7 \%$ versus $11 \pm 6.0 \%, P=0.22)$ (Table III).

At follow-up, OCT findings indicated that the BPEES group had a larger mean neointimal area than the 
Table I. Patient, Lesion, and Procedural Characteristics at Baseline

\begin{tabular}{|c|c|c|c|c|}
\hline & Total $(n=34)$ & DP-EES $(n=22)$ & BP-EES $(n=12)$ & $P$ value \\
\hline \multicolumn{5}{|l|}{ Patient characteristics } \\
\hline Male, $n(\%)$ & $22(65)$ & $14(64)$ & $8(67)$ & 0.86 \\
\hline Age, years & $72 \pm 8.2$ & $72 \pm 8.4$ & $70 \pm 7.8$ & 0.47 \\
\hline Body mass index, $\mathrm{kg} / \mathrm{m}^{2}$ & $24 \pm 2.6$ & $24 \pm 2.7$ & $24 \pm 2.7$ & 0.62 \\
\hline History of hypertension, $n(\%)$ & $31(91)$ & $19(86)$ & $12(100)$ & 0.18 \\
\hline History of dyslipidaemia, $n(\%)$ & $25(74)$ & $18(81)$ & $7(58)$ & 0.14 \\
\hline History of DM, $n(\%)$ & $19(56)$ & $13(59)$ & $6(50)$ & 0.61 \\
\hline History of stroke / TIA, $n(\%)$ & $2(5.9)$ & $1(4.6)$ & $1(8.3)$ & 0.65 \\
\hline History of PAD, $n(\%)$ & $5(15)$ & $4(18)$ & $1(8.3)$ & 0.44 \\
\hline History of CKD, $n(\%)$ & $5(14)$ & $3(14)$ & $2(17)$ & 0.81 \\
\hline Family history of CAD, $n(\%)$ & $4(12)$ & $4(18)$ & $0(0)$ & 0.12 \\
\hline Current smoker, $n(\%)$ & $8(24)$ & $6(27)$ & $2(17)$ & 0.49 \\
\hline LVEF, $(\%)$ & $64 \pm 13$ & $63 \pm 13$ & $64 \pm 4.1$ & 0.86 \\
\hline EGFR, $\mathrm{mL} /$ minute $/ 1.73 \mathrm{~m}^{2}$ & $60 \pm 2.6$ & $63 \pm 17$ & $55 \pm 9.1$ & 0.09 \\
\hline LDL cholesterol, mg/dL & $99 \pm 28$ & $101 \pm 28$ & $96 \pm 29$ & 0.58 \\
\hline $\mathrm{HbAlc},(\%)$ & $6.4[5.9-7.6]$ & $6.4[5.9-7.3]$ & $6.4[5.8-8.1]$ & 0.72 \\
\hline \multicolumn{5}{|l|}{ Medication just before PCI } \\
\hline Aspirin, $n(\%)$ & $32(94)$ & $20(91)$ & $12(100)$ & 0.28 \\
\hline Clopidogrel, $n(\%)$ & $23(68)$ & $17(77)$ & $6(50)$ & 0.10 \\
\hline Prasugrel, $n(\%)$ & $10(29)$ & $4(18)$ & $6(50)$ & 0.052 \\
\hline Beta blocker, $n(\%)$ & $14(41)$ & $11(50)$ & $3(25)$ & 0.16 \\
\hline Statin, $n(\%)$ & $24(71)$ & $17(77)$ & $7(58)$ & 0.25 \\
\hline \multicolumn{5}{|l|}{ Lesion characteristics } \\
\hline \multicolumn{5}{|l|}{ Target vessel } \\
\hline $\mathrm{LAD}, n(\%)$ & $31(91)$ & $20(91)$ & $11(92)$ & 0.94 \\
\hline $\mathrm{LCX}, n(\%)$ & $2(5.9)$ & $1(4.6)$ & $1(8.3)$ & 0.65 \\
\hline $\mathrm{RCA}, n(\%)$ & $1(2.9)$ & $1(4.6)$ & $0(0)$ & 0.45 \\
\hline \multicolumn{5}{|l|}{ ACC/AHA Lesion type } \\
\hline $\mathrm{B} 2, n(\%)$ & $9(27)$ & $4(18)$ & $5(42)$ & 0.14 \\
\hline $\mathrm{C}, n(\%)$ & $25(74)$ & $18(82)$ & $7(58)$ & 0.14 \\
\hline Calcification, $n(\%)$ & $34(100)$ & $22(100)$ & $12(100)$ & 1.00 \\
\hline Chronic total occlusion, $n(\%)$ & $2(5.9)$ & $1(4.6)$ & $1(8.3)$ & 0.65 \\
\hline Ostium, $n(\%)$ & $7(21)$ & $6(27)$ & $1(8.3)$ & 0.19 \\
\hline Bifurcation, $n(\%)$ & $9(27)$ & $5(23)$ & $4(33)$ & 0.50 \\
\hline \multicolumn{5}{|l|}{ Procedural characteristics } \\
\hline \multicolumn{5}{|l|}{ Rotational atherectomy } \\
\hline Use of 2 burrs, $n(\%)$ & $10(29)$ & $8(36)$ & $2(17)$ & 0.69 \\
\hline \multicolumn{5}{|l|}{ Burr size } \\
\hline $1.25 \mathrm{~mm}, n(\%)$ & $6(18)$ & $4(18)$ & $2(17)$ & 0.91 \\
\hline $1.5 \mathrm{~mm}, n(\%)$ & $25(74)$ & $17(77)$ & $8(67)$ & 0.50 \\
\hline $1.75 \mathrm{~mm}, n(\%)$ & $14(41)$ & $10(46)$ & $4(41)$ & 0.49 \\
\hline \multicolumn{5}{|l|}{ Stent } \\
\hline Number of stents, $n$ & $1[1-2]$ & $1[1-2]$ & $1[1-1]$ & 0.14 \\
\hline \multicolumn{5}{|l|}{ Stent diameter } \\
\hline Max stent diameter, $\mathrm{mm}$ & $2.9[2.5-3.3]$ & $3.0[2.5-3.5]$ & $2.6[2.5-3.0]$ & 0.18 \\
\hline Minimum stent diameter, $\mathrm{mm}$ & $2.5[2.5-2.8]$ & $2.5[2.5-2.8]$ & $2.5[2.5-2.9]$ & 0.71 \\
\hline \multicolumn{5}{|l|}{ Stent length } \\
\hline Max stent length, mm & 36 [28-38] & $36[28-38]$ & 35 [28-38] & 0.76 \\
\hline Minimum stent length, mm & 28 [22-38] & $28[22-34]$ & 28 [21-38] & 0.84 \\
\hline Post balloon dilatation, $n(\%)$ & $30(88)$ & $20(91)$ & $10(83)$ & 0.51 \\
\hline
\end{tabular}

Data are expressed as number or mean \pm standard deviation or median (interquartile range). DP-EES indicates durable polymer everolimus eluting stent; BP-EES, bioabsorbable polymer everolimus eluting stent; DM, diabetes mellitus; TIA, transient ischemic attack; PAD, peripheral artery disease; CKD, chronic kidney disease; CAD, coronary artery disease; and LVEF, left ventricular ejection fraction; EGFR, estimated glomerular filtration rate; LDL, low density lipoprotein; PCI, percutaneous coronary intervention; LAD, left anterior descending artery; LCX, left circumflex artery; RCA, right coronary artery; ACC, American College of Cardiology; and AHA, American Heart Association

DP-EES group $\left(0.7 \pm 0.4 \mathrm{~mm}^{2}\right.$ versus $1.1 \pm 0.4 \mathrm{~mm}^{2}, P<$ 0.01 ), and it also revealed that the BP-EES group had a higher percentage of covered and well-apposed struts than that of the DP-EES group $(95 \pm 4.5 \%$ versus $97 \pm 3.7 \%$, $P=0.045$ ) (Table IV). Furthermore, with regard to lesionlevel analysis, the BP-EES group had lesions with CS < 
Table II. Quantitative Coronary Angiography Analysis

\begin{tabular}{|c|c|c|c|c|}
\hline & Total $(n=34)$ & DP-EES $(n=22)$ & BP-EES $(n=12)$ & $P$ value \\
\hline \multicolumn{5}{|l|}{ Pre-procedure } \\
\hline Lesion length, mm & $29[13-45]$ & 33 [14-46] & $16[16-32]$ & 0.08 \\
\hline Reference diameter, mm & $2.2 \pm 0.6$ & $2.3 \pm 0.6$ & $2.0 \pm 0.4$ & 0.15 \\
\hline Minimum lumen diameter, $\mathrm{mm}$ & $0.6 \pm 0.3$ & $0.6 \pm 0.3$ & $0.5 \pm 0.2$ & 0.13 \\
\hline Diameter stenosis, $\%$ & $74 \pm 12$ & $73 \pm 12$ & $75 \pm 12$ & 0.59 \\
\hline \multicolumn{5}{|l|}{ Post-procedural } \\
\hline Minimum lumen diameter, $\mathrm{mm}$ & $1.8 \pm 0.4$ & $1.8 \pm 0.4$ & $1.8 \pm 0.5$ & 0.96 \\
\hline Diameter stenosis, \% & $6.4[3.4-11]$ & $6.7[3.4-13]$ & $5.6[1.6-8.9]$ & 0.19 \\
\hline Acute lumen gain, mm & $1.2 \pm 0.5$ & $1.2 \pm 0.5$ & $1.3 \pm 0.5$ & 0.38 \\
\hline \multicolumn{5}{|l|}{ 9-month follow-up } \\
\hline Reference diameter, $\mathrm{mm}$ & $2.4 \pm 0.4$ & $2.4 \pm 0.5$ & $2.5 \pm 0.3$ & 0.95 \\
\hline Minimum lumen diameter, $\mathrm{mm}$ & $1.5 \pm 0.4$ & $1.5 \pm 0.4$ & $1.5 \pm 0.4$ & 0.94 \\
\hline Diameter stenosis, \% & $21[11-31]$ & $21[11-34]$ & $20[6.9-29]$ & 0.37 \\
\hline Late lumen loss, mm & $0.3 \pm 0.4$ & $0.3 \pm 0.4$ & $0.3 \pm 0.4$ & 0.99 \\
\hline
\end{tabular}

Data are expressed as number or mean \pm standard deviation or median (interquartile range). DP-EES indicates durable polymer everolimus eluting stent; and BP-EES, bioabsorbable polymer everolimus eluting stent

Table III. Periprocedural Optical Coherence Tomography Findings

\begin{tabular}{|c|c|c|c|c|}
\hline & Total $(n=34)$ & DP-EES $(n=22)$ & BP-EES $(n=12)$ & $P$ value \\
\hline \multicolumn{5}{|l|}{ Preprocedural } \\
\hline \multicolumn{5}{|l|}{ Calcium character } \\
\hline Spotty, \% & $10(29)$ & $8(36)$ & $2(17)$ & 0.23 \\
\hline Sheet, \% & $24(71)$ & $14(63)$ & $10(83)$ & 0.23 \\
\hline Calcified nodule, $\%$ & $0(0)$ & $0(0)$ & $0(0)$ & - \\
\hline Calcium arc, ${ }^{\circ}$ & 360 [297-360] & $360[299-360]$ & $323[262-360]$ & 0.33 \\
\hline Minimum calcium thickness, $\mathrm{mm}$ & $0.4 \pm 0.2$ & $0.4 \pm 0.2$ & $0.4 \pm 0.2$ & 0.79 \\
\hline Calcium length, mm & $26[23-38]$ & $26[22-34]$ & 28 [24-39] & 0.46 \\
\hline \multicolumn{5}{|l|}{ Postprocedural } \\
\hline \multicolumn{5}{|l|}{ Cross-section analysis } \\
\hline Mean lumen area, $\mathrm{mm}^{2}$ & $5.5 \pm 1.1$ & $5.4 \pm 1.2$ & $5.8 \pm 1.1$ & 0.39 \\
\hline Minimum lumen area, $\mathrm{mm}^{2}$ & $3.7 \pm 1.0$ & $3.6 \pm 1.2$ & $3.9 \pm 0.7$ & 0.53 \\
\hline Minimal lumen diameter, $\mathrm{mm}$ & $2.0 \pm 0.3$ & $1.9 \pm 0.1$ & $2.0 \pm 0.1$ & 0.29 \\
\hline Lumen symmetry index & $1.2[1.1-1.3]$ & $1.2[1.1-1.3]$ & $1.2[1.0-1.2]$ & 0.24 \\
\hline In-stent lumen expansion, $\%$ & $70 \pm 18$ & $68 \pm 19$ & $75 \pm 17$ & 0.23 \\
\hline Maximum malapposition distance, $\mathrm{mm}$ & $0.5[0.3-0.7]$ & $0.4[0.2-0.5]$ & $0.6[0.5-0.8]$ & 0.02 \\
\hline Malapposition length, mm & $4.2 \pm 3.5$ & $3.8 \pm 3.5$ & $4.9 \pm 3.4$ & 0.14 \\
\hline Intra-stent plaque / stent area, $\%$ & $8.4 \pm 3.3$ & $8.3 \pm 3.7$ & $8.6 \pm 2.3$ & 0.81 \\
\hline Distal ED, $n(\%)$ & $8(24)$ & $7(32)$ & $1(8)$ & 0.12 \\
\hline Proximal ED, $n(\%)$ & $8(24)$ & $6(27)$ & $2(17)$ & 0.19 \\
\hline \multicolumn{5}{|l|}{ Strut-level analysis } \\
\hline Number of struts, $n$ & 11823 & 8612 & 3211 & \\
\hline Percentage of well-apposed struts, $\%$ & $90 \pm 6.4$ & $91 \pm 6.7$ & $89 \pm 6.0$ & 0.51 \\
\hline Percentage of malapposed struts, $\%$ & $10 \pm 6.4$ & $9.5 \pm 6.7$ & $11 \pm 6.0$ & 0.22 \\
\hline
\end{tabular}

Data are expressed as number or mean \pm standard deviation or median (interquartile range). DP-EES indicates durable polymer everolimus eluting stent; BP-EES, bioabsorbable polymer everolimus eluting stent; and ED, edge dissection.

$30 \%$ of uncovered struts than those of the DP-EES group (Figure 3).

In the univariate analyses, only BP-EES was significant, and three variables, prasugrel, BP-EES, and type C lesion were included in the multivariate logistic regression analysis. As a result, BP-EES resulted in being an independent factor of greater strut coverage (OR: 10.229 [95\% confidence interval: 1.627-64.325], $P=0.013$ ) (Table V).

\section{Discussion}

In the present study, BP-EES achieved a higher rate of neointimal strut coverage than DP-EES at the follow-up evaluation although the percentage of stent strut apposition was similar between the DP-EES group and the BPEES group immediately after PCI. A new finding in this study was the evaluation of neointimal responses in severely calcified lesions treated by RA with BP-EES or DP-EES deployment.

Acute stent strut malapposition can be observed at 
Table IV. Optical Coherence Tomography Analysis Results at Follow-Up

\begin{tabular}{|c|c|c|c|c|}
\hline & Total $(n=34)$ & DP-EES $(n=22)$ & $\operatorname{BP}-\operatorname{EES}(n=12)$ & $P$ value \\
\hline \multicolumn{5}{|l|}{ Lesion level and cross-section level analysis } \\
\hline Mean lumen area, mm & $4.7 \pm 1.3$ & $4.7 \pm 1.4$ & $4.7 \pm 1.0$ & 0.98 \\
\hline Mean stent area, $\mathrm{mm}$ & $5.5 \pm 1.1$ & $5.3 \pm 1.4$ & $5.7 \pm 1.1$ & 0.40 \\
\hline Mean neointimal area, $\mathrm{mm}^{2}$ & $0.8 \pm 0.4$ & $0.7 \pm 0.4$ & $1.1 \pm 0.4$ & $<0.01$ \\
\hline Mean neointimal volume, $\mathrm{mm}^{3}$ & $31 \pm 19$ & $28 \pm 19$ & $37 \pm 19$ & 0.68 \\
\hline Number of cross-section, $n$ & 1350 & 949 & 401 & \\
\hline Percentage of cross-sections with $\geq 30 \%$ uncovered struts, $\%$ & $2.2[0-5.2]$ & $3.1[0-6.6]$ & $0[0-0]$ & $<0.01$ \\
\hline Percentage of cross-section with $\geq 5 \%$ malapposed struts, $\%$ & $0.7[0-6.3]$ & $2.1[0-7.8]$ & $0[0-5.7]$ & 0.50 \\
\hline Percentage of cross-section with $\geq 10 \%$ malapposed struts, $\%$ & $0.7[0-4.9]$ & $1.5[0-5.2]$ & $0[0-4.6]$ & 0.69 \\
\hline \multicolumn{5}{|l|}{ Strut-level analysis } \\
\hline Number of struts, $n$ & 11720 & 8212 & 3508 & \\
\hline Percentage of covered and well-apposed struts, $\%$ & $95 \pm 4.3$ & $95 \pm 4.5$ & $97 \pm 3.7$ & 0.045 \\
\hline Percentage of uncovered struts, $\%$ & $3.1[1.0-5.2]$ & $3.5[2.2-7.3]$ & $1.3[0.4-4.0]$ & 0.04 \\
\hline Percentage of malapposed struts, $\%$ & $0[0-0.8]$ & $0.1[0-1.0]$ & $0[0-0.7]$ & 0.67 \\
\hline Lesion-level analysis & \multicolumn{4}{|c|}{ (accounting for potential clustering effect) } \\
\hline Number of stents, $n$ & 48 & 34 & 14 & \\
\hline Stents with all cross sections $<30 \%$ uncovered struts, $n(\%)$ & $25(52)$ & $13(38)$ & $12(86)$ & $<0.01$ \\
\hline Lesions with all cross sections $<30 \%$ uncovered struts, $n(\%)$ & $16(47)$ & $6(27)$ & $10(83)$ & $<0.01$ \\
\hline
\end{tabular}

Data are expressed as number or mean \pm standard deviation or median (interquartile range). DP-EES indicates durable polymer everolimus eluting stent; and BP-EES, bioabsorbable polymer everolimus eluting stent.

Lesions with all cross section $<30 \%$ uncovered struts

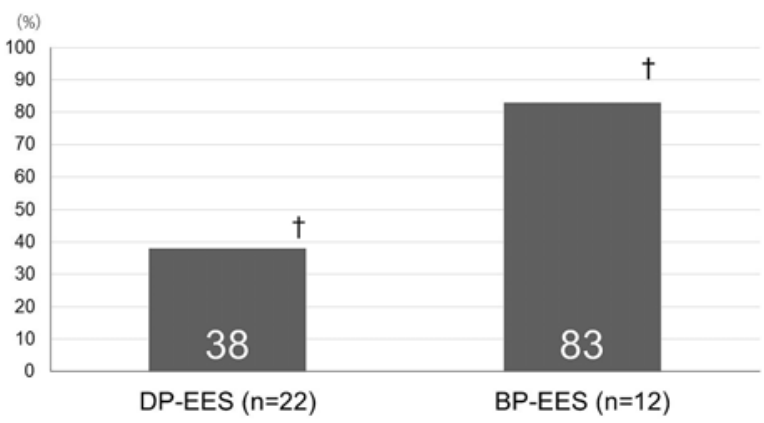

Figure 3. Lesion-level analysis at follow-up. The bar graphs show that the percentage of lesions with all cross-section $<30 \%$ uncovered struts in the bioabsorbable-polymer everolimus-eluting stent group was higher than that in the durable-polymer everolimus-eluting stent group. ${ }^{\dagger} P=0.017$ for percentage of lesions with all cross sections $<30 \%$ uncovered struts. DP-EES indicates durable polymer everolimus eluting stent; and BP-EES, bioabsorbable-polymer everolimus eluting stent

stent implantation. The mechanism behind this finding is thought to be associated with a procedural matter, and additional balloon angioplasty is often performed to resolve it. Shimamura et al. reported that the stent struts with acute maximum malapposition distance $<355 \mu \mathrm{m}$ immediately after second-generation EES implantation could resolve spontaneously at 8-12-month follow-up, ${ }^{16)}$ but maximum malapposition distance immediately after PCI in this study was longer than that of the previous study, this being because there was difficulty in making all stent struts well-apposed in severely calcified lesions whose vessel lumen had very rugged surfaces.

With regard to the first-generation drug-eluting stents equipped DP, excessive inhibition of neointimal formation caused delayed endothelial impairment, ${ }^{7-9)}$ with the inadequate stent strut endothelial coverage after drug-eluting stent deployment being associated with late stent thrombo- sis. These characteristics might appear prominent in severely calcified lesions as the present study populations, where it is considered to take a long time to recover endothelialization. The second-generation drug-eluting stent was invented to improve these problems. A coronary injury model of the familial hypercholesterolemic swine demonstrated the efficacy of EES platforms, with everolimus eluted from different polymeric platforms resulting in lower levels of inflammation and slightly higher fibrin deposits at one month after stent implantation. ${ }^{17,18)}$ Moreover, an OCT study evaluating early EES responses showed that the malapposition of stent struts completely disappeared at four weeks after stent implantation, and almost all neointimal coverage of stent struts was achieved within 12 weeks. ${ }^{19)}$ A meta-analysis of DES evaluated the overall best combination of healing with suppression of neointimal hyperplasia at 6-12 months, ${ }^{20)}$ which displayed that EES performed better results than any other types of DES. A recent study assessing the BP-EES strut response for acute coronary syndrome lesions reported that BP-EES resulted in an earlier neointimal coverage than conventional DP-EES. ${ }^{21)}$ In this study, DP was composed of fluoropolymer that allows drug eluting for a long period. On the other hand, BP was made of polylactic-co-glycolic acid which enables eluting of the drug and degrading for a shorter duration (three to four months). In addition, BPEES differs from DP-EES in terms of the polymer coating technique, and the former may also result in a better partial neointimal response. ${ }^{22}$

The neointimal response to BP-EES struts in severely calcified lesions requiring RA has never been well characterized to date. Although $50 \%-60 \%$ of the total lesions evaluated in the EVOLVE trial, which was the first BPEES trial in humans, were of types $\mathrm{B} 2$ or $\mathrm{C}$, the rate of severely calcified lesions was not mentioned..$^{23,24)}$ Therefore, our present study provides new evidence in this context. A previous report showed that the prognosis of patients with severely calcified lesions treated with RA was 
Table V. Clinical Factors and OCT Findings Associating with Greater Strut Coverage

\begin{tabular}{lcccc}
\hline & \multicolumn{2}{c}{ Univariate analysis } & \multicolumn{2}{c}{ Multivariate analysis } \\
& OR $(95 \% \mathrm{CI})$ & $P$ value & OR $(95 \% \mathrm{CI})$ & $P$ value \\
\hline Hypertension & $0.412(0.034-5.029)$ & 0.487 & & \\
Dyslipidaemia & $0.333(0.059-1.573)$ & 0.179 & & \\
Diabetes millennium & $0.636(0.158-2.481)$ & 0.515 & & \\
Prasugrel & $3.889(0.849-21.854)$ & 0.081 & $2.136(0.330-13.818)$ & 0.425 \\
BP-EES & $13.333(2.608-105.519)$ & 0.001 & $10.229(1.627-64.325)$ & 0.013 \\
Type C lesion & $0.333(0.059-1.573)$ & 0.167 & $0.542(0.080-3.655)$ & 0.530 \\
Greater estimated glomerular filtration rate & $0.980(0.929-1.025)$ & 0.396 & & \\
Greater \% diameter stenosis at post-procedural & $0.925(0.819-1.046)$ & 0.214 & & \\
Greater maximum malapposition distance & $1.886(0.122-32.525)$ & 0.647 & & \\
Distal edge dissection & $0.600(0.105-2.972)$ & 0.534 & & \\
\hline OCT
\end{tabular}

OCT indicates optical coherence tomography; OR, odds ratio; CI, confidence interval; and BP-EES, bioabsorbable polymer everolimus eluting stent

poor, and that the cumulative five-year incidence of allcause death in this population was up to $34.9 \% .^{25)}$ Likewise, the three-year outcome of target lesion failure in calcified lesions may be approximately two-fold higher than that in those without similar lesions. ${ }^{26)}$ The greater neointimal coverage at the late phase may avoid stent failures in the long term even though excessive neointimal hyperplasia may result in in-stent restenosis. ${ }^{27)}$ Nonetheless, our results alone are insufficient to explain that BPEES prevents long-term stent failure. Thus, further study is warranted.

BP-EES may not always achieve better outcomes than DP-EES. For instance, Sato, et al. ${ }^{28)}$ compared clinical outcomes with EES implantation in patients with endstage chronic kidney disease on hemodialysis. According to their study, a tendency toward higher target lesion revascularization was observed for the BP-EES group $(22.7 \%)$ than for the DP-EES groups $(P=0.07)$. This data set included angiographic characteristics at baseline, and the reported rate of severe calcification grade was not comparably high $(16.3 \%)$, which was entirely different from that observed in our cohort at baseline. Thus, BPEES should not be applied in such patients.

The DP-EES group in the present cohort included cobalt-chromium DP-EES and platinum-chromium DPEES. Previous reports have shown that both agents presented very similar neointimal coverage and long-term clinical outcomes could be achieved. ${ }^{29-33}$ Therefore, we considered both types of DP-EES as the same subject population and described this point in limitations.

In the present study, univariate analysis identified only one significant variable of greater neointimal coverage: BP-EES. Furthermore, multivariate analysis showed that BP-EES was an independent factor of greater neointimal coverage. Previous reports said that neointimal hyperplasia after bare metal stent implantation was related to several patient characteristics such as diabetes mellitus and dyslipidemia. ${ }^{34-36}$ Potentially, the patient or lesion characteristics might have had an influence on neointimal response, but these categories were not shown to be a statistically independent factor associated with greater neointimal coverage at nine months after PCI on logistic regression analyses. Therefore, we might be able to demonstrate that the BP-EES had an impact on the neointimal cover- age response nine months after PCI.

Limitations: Firstly, given the limited study population enrolled at a single center and the retrospective study design, the potential for selection bias and recall bias cannot be overlooked. Secondly, because of the difficulty in passing the devices or due to an insufficient removal of blood cells, not all lesions were observed by OCT imaging devices. Thirdly, lesion characteristics, such as the rate of prasugrel prescription and the estimated glomerular filtration rate, may have represented a selection bias. Fourthly, there were some difficulties in confining the analysis to the cases wherein the same stent designs were used because of the small sample size of the present study and its retrospective nature. Fifthly, there were difficulties in selecting more than three variables for multivariate analysis, given the limited number of outcomes. Finally, as mentioned in discussion, the DP-EES group included both cobalt-chromium DP-EES and platinum-chromium DPEES.

\section{Conclusions}

The present study showed that BP-EES achieved better neointimal coverage than DP-EES at nine months after PCI in severely calcified lesions, especially requiring RA. This study had several limitations, so that further prospective studies are needed to validate this finding.

\section{Acknowledgments}

We are grateful to Editage (www.editage.jp) for English language editing.

\section{Disclosure}

Conflicts of interest: The authors declare that there is no conflict of interest regarding the publication of this paper.

\section{References}

1. Zhang BC, Wang C, Li WH, Li DY. Clinical outcome of drugeluting versus bare-metal stents in patients with calcified coronary lesions: a meta-analysis. Intern Med J 2015; 45: 203-11. 
2. Kedhi E, Joesoef KS, McFadden E, et al. Second-generation everolimus-eluting and paclitaxel-eluting stents in real-life practice (COMPARE): a randomised trial. Lancet 2010; 375: 201-9.

3. Harjai KJ, Kondareddy S, Pinkosky B, Harjai N, Orshaw P, Boura J. Everolimus-eluting stents versus sirolimus- or paclitaxel-eluting stents: two-year results from the Guthrie Health Off-Label Stent (GHOST) registry. J Interv Cardiol 2013; 26: 153-62.

4. Tian W, Mahmoudi M, Lhermusier T, et al. Clinical outcomes of first- and second-generation drug-eluting stents in patients undergoing rotational atherectomy for heavily calcified coronary lesions. Cardiovasc Revasc Med 2015; 16: 147-50.

5. Jiang J, Sun Y, Xiang MX, et al. Complex coronary lesions and rotational atherectomy: one hospital's experience. J Zhejiang Univ Sci B 2012; 13: 645-51.

6. Tian W, Lhermusier T, Minha S, Waksman R. Rational use of rotational atherectomy in calcified lesions in the drug-eluting stent era: review of the evidence and current practice. Cardiovasc Revasc Med 2015; 16: 78-83.

7. Finn AV, Joner M, Nakazawa G, et al. Pathological correlates of late drug-eluting stent thrombosis: strut coverage as a marker of endothelialization. Circulation 2007; 115: 2435-41.

8. Finn AV, Nakazawa G, Joner M, et al. Vascular responses to drug eluting stents: importance of delayed healing. Arterioscler Thromb Vasc Biol 2007; 27: 1500-10.

9. Joner M, Finn AV, Farb A, et al. Pathology of drug-eluting stents in humans: delayed healing and late thrombotic risk. J Am Coll Cardiol 2006; 48: 193-202.

10. Tomey MI, Kini AS, Sharma SK. Current status of rotational atherectomy. JACC Cardiovasc Interv 2014; 7: 345-53.

11. Zimarino M, Corcos T, Bramucci E, Tamburino C. Rotational atherectomy: a "survivor" in the drug-eluting stent era. Cardiovasc Revasc Med 2012; 13: 185-92.

12. Di Vito L, Yoon JH, Kato K, et al. Comprehensive overview of definitions for optical coherence tomography-based plaque and stent analyses. Coron Artery Dis 2014; 25: 172-85.

13. Tearney GJ, Regar E, Akasaka T, et al. Consensus standards for acquisition, measurement, and reporting of intravascular optical coherence tomography studies: a report from the International Working Group for Intravascular Optical Coherence Tomography Standardization and Validation. J Am Coll Cardiol 2012; 59: 1058-72.

14. Fujii K, Kubo T, Otake H, et al. Expert consensus statement for quantitative measurement and morphological assessment of optical coherence tomography. Cardiovasc Interv Ther 2020; 35 13-8.

15. Sugiyama T, Yamamoto E, Fracassi F, et al. Calcified plaques in patients with acute coronary syndromes. JACC Cardiovasc Interv $2019 ; 12: 531-40$

16. Shimamura K, Kubo $\mathrm{T}$, Akasaka $\mathrm{T}$, et al. Outcomes of everolimus-eluting stent incomplete stent apposition: a serial optical coherence tomography analysis. Eur Heart J Cardiovasc Imaging 2015; 16: 23-8.

17. Tellez A, Seifert PS, Donskoy E, et al. Experimental evaluation of efficacy and healing response of everolimus-eluting stents in the familial hypercholesterolemic swine model: a comparative study of bioabsorbable versus durable polymer stent platforms. Coron Artery Dis 2014; 25: 198-207.

18. Palmerini T, Biondi-Zoccai G, Stone GW. Stent selection to minimize the risk of stent thrombosis. Curr Opin Cardiol 2014; 29: $578-85$

19. Yano H, Horinaka S, Ishikawa M, Ishimitsu T. Early vascular responses after everolimus-eluting stent implantation assessed by serial observations of intracoronary optical coherence tomography. Heart Vessels 2017; 32: 804-12.

20. Iannaccone M, D'Ascenzo F, Templin C, et al. Optical coherence tomography evaluation of intermediate-term healing of different stent types: systemic review and meta-analysis. Eur Heart J Cardiovasc Imaging 2017; 18: 159-66.

21. Shimoda M, Ando H, Naito K, et al. Early-phase vascular healing of bioabsorbable vs. durable polymer-coated everolimus- eluting stents in patients with st-elevation myocardial infarction 2-week and 4-month analyses with optical coherence tomography. Circ J 2018; 82: 2594-601.

22. Shreenivas SS, Kereiakes DJ. Evolution of the SYNERGY bioresorbable polymer metallic coronary stent. Future Cardiol 2018; 14: 307-17.

23. Meredith IT, Verheye S, Dubois CL, et al. Primary endpoint results of the EVOLVE trial: a randomized evaluation of a novel bioabsorbable polymer-coated, everolimus-eluting coronary stent. J Am Coll Cardiol 2012; 59: 1362-70.

24. Meredith IT, Verheye S, Weissman NJ, et al. Six-month IVUS and two-year clinical outcomes in the EVOLVE FHU trial: a randomised evaluation of a novel bioabsorbable polymer-coated, everolimus-eluting stent. EuroIntervention 2013; 9: 308-15.

25. Jinnouchi H, Kuramitsu S, Shinozaki T, et al. Five-year clinical outcomes after drug-eluting stent implantation following rotational atherectomy for heavily calcified lesions. Circ J 2018; 82: 983-91.

26. Nishida K, Nakatsuma K, Shiomi H, et al. Second-generation vs. first-generation drug-eluting stents in patients with calcified coronary lesions- pooled analysis from the RESET and NEXT trials. Circ J 2018; 82: 376-87.

27. Buccheri D, Piraino D, Andolina G, Cortese B. Understanding and managing in-stent restenosis: a review of clinical data, from pathogenesis to treatment. J Thorac Dis 2016; 8: E1150-62.

28. Sato T, Hatada K, Kishi S, et al. Comparison of clinical outcomes of coronary artery stent implantation in patients with end-stage chronic kidney disease including hemodialysis for three everolimus eluting (EES) stent designs: bioresorbable polymer-EES, platinum-chromium-EES, and cobalt chromeEES. J Interv Cardiol 2018; 31: 170-6.

29. Meredith IT, Teirstein PS, Bouchard A, et al. Three-year results comparing platinum-chromium PROMUS element and cobaltchromium XIENCE V everolimus-eluting stents in de novo coronary artery narrowing (from the PLATINUM Trial). Am J Cardiol 2014; 113: 1117-23.

30. Li RG, Lee CH, Low A, et al. Comparison of platinum chromium everolimus-eluting stent with cobalt chromium everolimus-eluting stent in unselected patients undergoing percutaneous coronary intervention. Eur Rev Med Pharmacol Sci 2015; 19: 2213-20.

31. Kim BK, Shin DH, Kim JS, et al. Randomized comparison of acute stent malapposition between platinum-chromium versus cobalt-chromium everolimus-eluting stents. Int J Cardiovasc Imaging 2015; 31: 269-77.

32. van Bommel RJ, Lemmert ME, van Mieghem NM, van Geuns RJ, van Domburg RT, Daemen J. Occurrence and predictors of acute stent recoil-A comparison between the xience prime cobalt chromium stent and the promus premier platinum chromium stent. Catheter Cardiovasc Interv 2018; 91: E21-8.

33. Guagliumi G, Capodanno D, Ikejima H, et al. Impact of different stent alloys on human vascular response to everolimuseluting stent: an optical coherence tomography study: the OCTEVEREST. Catheter Cardiovasc Interv 2013; 81: 510-8.

34. Gilbert J, Raboud J, Zinman B. Meta-analysis of the effect of diabetes on restenosis rates among patients receiving coronary angioplasty stenting. Diabetes Care 2004; 27: 990-4.

35. Tellez A, Krueger CG, Seifert P, et al. Coronary bare metal stent implantation in homozygous LDL receptor deficient swine induces a neointimal formation pattern similar to humans. Atherosclerosis 2010; 213: 518-24.

36. Scott NA. Restenosis following implantation of bare metal coronary stents: pathophysiology and pathways involved in the vascular response to injury. Adv Drug Deliv Rev 2006; 58: 358-76.

\section{Supplemental Files}

Supplemental Tables I, II

Please see supplemental files; https://doi.org/10.1536/ihj.19-648 